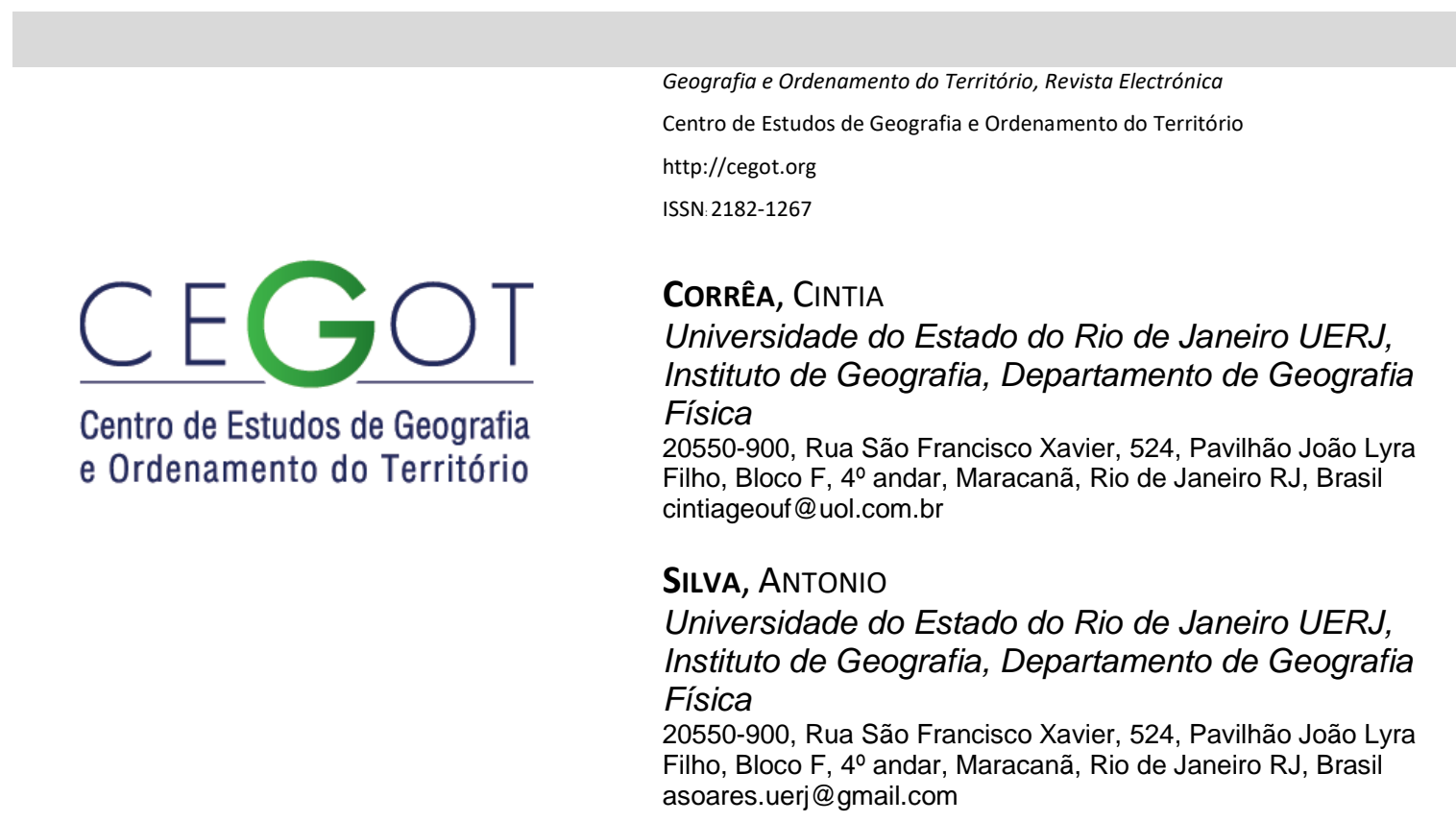

\title{
Considerações sobre a redução/ampliação da dimensão de áreas de preservação permanente de faixa marginal de curso d'água em três áreas no Rio Paraíba do Sul - RJ, Brasil
}

Considerations on the reduction/extension of the permanent preservation areas of the marginal watercourse in three areas in the Paraíba do Sul River RJ, Brazil

Referência: Corrêa, Cintia; Silva, Antonio (2017). Considerações sobre a redução/ampliação da dimensão de áreas de preservação permanente de faixa marginal de curso d'água em três áreas no Rio Paraíba do Sul - RJ, Brasil. Revista de Geografia e Ordenamento do Território (GOT), n.o 11 (junho). Centro de Estudos de Geografia e Ordenamento do Território, p. 125-147, dx.doi.org/10.17127/got/2017.11.006

\section{RESUMO}

No Brasil, as áreas marginais de curso d'água (FMPs) são áreas de preservação permanente (APPs) protegidas pelo Código Florestal (Lei 12.651/2012). As APPs urbanas ou consolidadas são vulneráveis a enchentes e inundações. Neste cenário, comparam-se três áreas de APPs/ FMPs consolidas em diferentes contextos geológico-geomorfológicos às margens do Rio Paraíba do Sul (no Estado do Rio de Janeiro). Área 1 (Resende), Área 2 (Paraíba do Sul-Três Rios) e Área 3 (Campos dos Goytacazes). O objetivo é avaliar a possibilidade de ampliação/redução das APPs/ FMPs consolidadas, de acordo com os instrumentos legais regulatórios. Quanto a metodologia, realizou-se mapeamentos e caracterização do uso da terra com o software ArcGis 10.3 validados em campo. De acordo com os resultados, conclui-se que é possível alterar as dimensões destas áreas desde que sejam elaborados estudos detalhados quando solicitada a intervenção. 
Palavras-chave: Áreas de preservação permanente de faixa marginal de curso d'água; Rio Paraíba do Sul; Uso da terra em FMPs; APPs em áreas urbanas.

\section{ABSTRACT}

In Brazil, the marginal watercourse areas (FMPs) are permanent preservation areas (APPs) protected by the Forest Code (Law 12.651/2012). Urban or consolidated APPs are vulnerable to floods and inundations. In this scenario, three areas of consolidated APPs / FMPs are compared in different geological-geomorphological contexts along the Paraíba do Sul River (in the State of Rio de Janeiro). Area 1 (Resende), Area 2 (Paraíba do Sul-Três Rios) and Area 3 (Campos dos Goytacazes). The objective is to evaluate the possibility of enlargement/reduction of the consolidated APPs/FMPs, in accordance with the legal regulatory instruments. As for the methodology, land-use mapping and characterization with field-validation, using ArcGis 10.3 software was performed. According to the results, it is concluded that it is possible to change the dimensions of these areas provided that detailed studies are elaborated when the intervention is requested.

Keywords: Areas of permanent preservation of marginal strip of watercourse; River Paraíba do Sul; Land use in FMPs; APPs in urban areas.

\section{Introdução}

As primeiras cidades se desenvolveram próximas aos rios devido, principalmente, à necessidade humana pelo acesso e captação de água, para o transporte e abastecimento de água e a eliminação de efluentes. E até os dias atuais, uma parte da população urbana permanece às margens dos rios, embora esta localização ribeirinha ainda seja vista de um modo que não é sustentável sob o ponto de vista ambiental.

No Brasil, as margens dos rios são consideradas Áreas de Preservação Permanente (APPs) instituídas por meio da Lei 12.651/2012 (BRASIL, 2012) com o objetivo de garantir a preservação das faixas marginais de curso d'água (FMPs), das áreas de nascentes, dos topos de morros, de encostas, entre outras:

\footnotetext{
"cobertas ou não por vegetação nativa, com a função ambiental de preservar os recursos hídricos, a paisagem, a estabilidade geológica, a biodiversidade, o fluxo gênico de fauna e flora, proteger o solo e assegurar o bem estar das populações humanas".

"de garantir a preservação das faixas marginais de curso d'agua (FMPs), das áreas de nascentes, dos topos de morros, de encostas, entre outras".
}

As dimensões e a aplicabilidade destas áreas geram diversas discussões. Discussões estas presentes desde que foram instituídas as APPs no Código Florestal Brasileiro (CFB) de 1965, 
e com poucos avançados relacionados ao descompasso entre questões urbanas, questões ambientais e normas vigentes.

No atual cenário, as cidades brasileiras são consolidadas em Áreas Protegidas com o uso da terra e a retirada da cobertura da terra associada a inúmeros eventos de enchentes e inundações, havendo uma estreita relação entre estes eventos e a ocupação de terrenos marginais de cursos d'água, ou seja, de APPs de FMPs (BRASIL, 2007). Estas APPs/ FMPs, por serem áreas suscetíveis e de baixa altimetria e por não atenderem ao que estabelece a legislação referente à dinâmica marginal dos rios e à proteção, são apontadas como fatores que contribuem para a baixa qualidade da água, assoreamento fluvial, erosão e solapamento das margens, degradação e impermeabilização de solos e outros problemas associados.

Para se proceder a uma exemplificação que considere as APPs, especialmente as FMPs, o Rio Paraíba do Sul no Estado do Rio de Janeiro, Brasil, tem o caráter de um facilitador dos estudos. O Paraíba do Sul é um importante rio do sudeste brasileiro. Nasce no Estado de São Paulo e atravessa todo o Estado fluminense, percorrendo mais de $1.100 \mathrm{~km}$. Abastece paulistas, fluminenses e mineiros com suas águas, além dos cerca de 9 milhões de habitantes da Região Metropolitana do Rio de Janeiro (MACHADO, 2012, p.22).

$\mathrm{Na}$ identificação dos segmentos do rio principal busca-se gerar uma representação territorial, agrupando características referentes aos aspectos ambientais no Vale do Rio Paraíba do Sul fluminense, duas áreas no médio vale do Paraíba, o vale do café fluminense, terras utilizadas pela cafeicultura no século XIX e degradadas por esta atividade. E por fim, uma área na baixada campista, próximo à foz do Paraíba com depósitos de sedimentos fluviais.

O conflito entre a ocupação de APPs na Bacia do Rio Paraíba do Sul em várias cidades, como Resende, Três Rios e Campos dos Goytacazes, é devido ao aumento da frequência das inundações relacionado à maior velocidade no escoamento superficial, impermeabilização de suas margens e ao assoreamento das calhas fluviais.

O que se vê, ainda, é o aumento da ocupação das áreas vulneráveis da cidade, o que presume a necessidade de um mapeamento e produção de material científico, no intuito de fornecer fundamentação para possíveis planos de gerenciamento que visem à mitigação dos efeitos das inundações, especialmente APPs de FMPs localizadas às margens do Paraíba do 
Sul (100 e 200 metros), bem como para futuras intervenções urbanas e regularizações ambientais. Este trabalho estuda uma área com tais características na Bacia do rio Paraíba do Sul e faz uma consideração da ocupação de três áreas diferentes, às margens do rio principal, o Rio Paraíba do Sul.

Assim, para o presente trabalho, partimos da discussão sobre se é possível ou não ampliar e/ ou reduzir as APPs/ FMPs em áreas urbanas, tendo por base o CFB, Lei 12.651/2012 (BRASIL, 2012).

Com base no que foi exposto, foi estabelecido como Objetivo Geral deste trabalho, considerar a literatura, os trabalhos que já vêm sendo realizados, avaliando o contexto, as modificações relativas aos instrumentos regulatórios que incidem sobre as APPs na legislação ambiental brasileira no que se refere à sua função original, transformações e conflitos, especialmente com relação às FMPs, discutindo a necessidade de se ampliar ou reduzir a dimensão destas faixas em áreas urbanas já consolidadas em três diferentes áreas a serem comparadas as margens do Rio Paraíba do Sul no Estado do Rio de Janeiro.

\section{2. Área de estudo}

Resende, Paraíba do Sul-Três Rios e Campos dos Goytacazes são as três Áreas de estudo, chamadas de Área 1, Área 2 e Área 3. Localizam-se às margens do Rio Paraíba do Sul, rio principal homônimo à bacia, em diferentes contextos geológico-geomorfológicos, em diferentes seções do Rio Paraíba do Sul, no Estado do Rio de Janeiro.

Resende, município que se localiza na Região do Médio Vale do Paraíba do Sul Fluminense, está inserido no terço médio da Bacia do Paraíba do Sul. É uma antiga região cafeeira e a desproteção de mananciais, deslizamento, erosão (causada pelo desmatamento), poluição de rios são problemas constantes. A área para estudo, Área 1 Resende, localiza-se na área urbana central do município de Resende, coordenada UTM 556594 m (Este) e 7515471 m (Norte) - fuso 23 Sul.

Já nos municípios de Paraíba do Sul e Três Rios localiza-se a segunda área para estudo, exatamente entre os dois municípios, Área 2 Paraíba do Sul-Três Rios, coordenada UTM 
681283 m (Este) e 7551544 m (Norte) - fuso 23 Sul, à margem esquerda do Rio Paraíba do Sul na Região Centro-Sul Fluminense, também uma antiga região cafeeira, inserida no médio curso da Bacia do Paraíba do Sul. É uma área de uso urbano que possui também pastagem e solo exposto.

A terceira e última área localiza-se em Campos dos Goytacazes na Região Norte Fluminense, Área 3 Campos dos Goytacazes, coordenada UTM 259743 m (Este) e 7592505 m (Norte) fuso 24 Sul (Figura 2). Localiza-se em uma área central do município, com uso urbano. É, sobretudo, uma região que se dedicava à produção da cana de açúcar e é a principal cidade do norte fluminense.

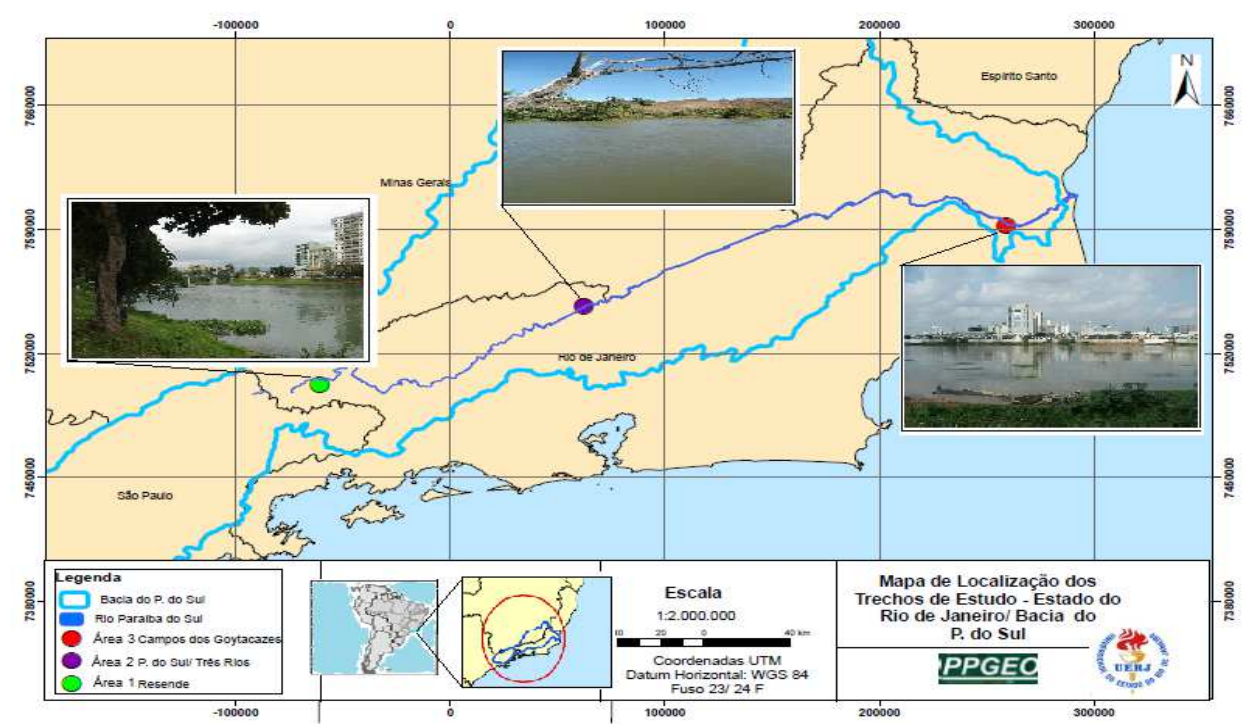

Figura 1 - Localização da Área 1 (Resende), Área 2 (Paraíba do Sul -Três Rios) e Área 3 (Campos dos Goytacazes) no Estado do Rio de Janeiro.

Fonte: INEA (2015). Adaptação e fotografias realizadas pelos autores em out. 2014 e abr.2015.

\section{Referencial teórico}

\section{1. Área de Preservação Permanente de Faixa Marginal de Curso d'água}

O tema relativo à Área de Preservação Permanente-APP está sendo amplamente discutido nos últimos anos e em diversos trabalhos, como "Áreas de preservação permanente na legislação ambiental brasileira" (BORGES, 2011) onde se discute a evolução das APPs desde 1965; "Áreas de Preservação Permanente e Unidades de Conservação \& Áreas de Risco" (BRASIL, 2011), realizado após a tragédia na Região Serrana do Rio de Janeiro e a discussão 
da ocupação de APPs e áreas de risco. Há, ainda, o trabalho realizado por Silva (2011), "Mineração e áreas de preservação permanentes (APPs) em Santo Antônio de Pádua - RJ", na identificação de empreendimentos em APPs, em que o mesmo sugere uma revisão da largura da FMP de 30 metros.

As APPs surgiram no CBF de 1965 (Lei 4.771/1965, BRASIL, 1965), quando foram extintas quatro tipologias de áreas protegidas pelo CFB de 1934 (Decreto 23.793 de 23 de janeiro de 1934): protetoras, remanescentes, modelo e de rendimento, e substituídas por Parque Nacional, Floresta Nacional, Floresta de Preservação Permanente (alterado posteriormente para Área de Preservação Permanente) e Reserva Legal (RESENDE, 2006, p.76; MEDEIROS, 2006, p. 46). Segundo Ahrens (2003, p. 9) e Costa (2010, p.44), tais mudanças ocorreram para garantir que os principais objetivos do CFB de 1965 fossem atendidos: "proteção dos solos contra a erosão, prevenção das águas, cursos d'água e reservatórios contra o assoreamento (...)".

Segundo Costa (2010, p.46/47), após 21 anos da promulgação da Lei 4771/1965, ocorreu sua primeira alteração, através da Lei 7.511 de 7 de julho 1986, que promoveu o primeiro aumento das dimensões/metragens das APPs de curso d'água e, em seguida, a Lei 7.803 de 18 de julho de 1989. Veja como são estabelecida as APP/ FMPs e suas larguras segundo o artigo 4으 (Lei 12.651/2012), inciso I,

I - as faixas marginais de qualquer curso d'água natural perene e intermitente, excluídos os efêmeros, desde a borda da calha regular, em largura mínima de:

a) 30 metros para os cursos d'água de menos de 10 metros de largura;

b) 50 metros para os cursos d'água que tenham de 10 a 50 metros de largura;

c) 100 metros para os cursos d'água que tenham de 50 a 200 metros de largura;

d) 200 metros para os cursos d'água que tenham de 200 a 600 metros de largura;

e) 500 metros para os cursos d'água que tenham largura superior a 600 metros;

Dentre as alterações instituídas pela nova legislação destacam-se as mudanças relacionadas às APPs que protegem as matas ciliares. Para a delimitação das APPs de matas ciliares, de acordo com a Lei $12.651 / 2012$, a referência passou a ser o leito regular do rio, enquanto 
que, na lei revogada, 4.771/1965, a referência para a delimitação era o seu nível mais alto de inundação.

Ao ser considerado o leito regular do rio como referência, o leito de cheia não é contemplado com a preservação e assim aumentam o risco de inundação nas futuras ocupações destas áreas.

\subsection{Uso da terra}

Em áreas protegidas, como as APPs, de uso consolidado, deve-se discutir propostas para regulamentar, flexibilizar e adequar os usos da terra, minimizando os efeitos da supressão da cobertura da terra e reafirmando a importância e função ambiental destas áreas. Para Araújo (2002, p.11), deve-se regularizar o uso da terra em áreas de baixa renda como pressuposto para controle e preservação de APPs ainda existentes, colocando-se me vista que em tal estudo, tratamos de um problema da ordem de planejamento urbano-ambiental.

\subsection{Vulnerabilidade, Risco e Suscetibilidade a Enchentes e Inundações}

Para Braga et al. (2006, p.2), nos últimos 30 anos ocorreram crescimento demográfico, mudanças socioeconômicas e aumento de populações urbanas, concentrando cada vez mais pessoas e bens em áreas com exposição a perigos naturais. As consequências atingem mais os pobres, minorias, mulheres, crianças e idosos, criando vulnerabilidades diferenciadas. Fenômenos naturais causam desastres somente quando associados à população exposta e com certo grau de vulnerabilidade, que resulta de fatores físicos, sociais, econômicos e ambientais, assim como de outros processos que aumentam a suscetibilidade aos impactos de um perigo.

A exposição refere-se ao que é afetado por desastres naturais, como pessoas e bens. A suscetibilidade é a predisposição a sofrer danos. A vulnerabilidade é entendida como a suscetibilidade a perigo ou dano, a incapacidade de uma pessoa, grupo ou sociedade de evitar o perigo de desastres naturais ou que é forçado a viver em tais condições, pela relação entre a fragilidade, localização (exposição) e ausência de resistência física à sua 
propagação. A fragilidade aborda em que medida um grupo populacional é suscetível de ser afetado por um fenômeno perigoso (BRAGA et al., 2013, p.5).

Para Esteves (2011, p.75), ao integrar as dimensões sociais e ambientais na identificação e análise da vulnerabilidade, admite a terminologia vulnerabilidade socioambiental, devido a interligar-se a fatores sociais, econômicos, tecnológicos, culturais e ao ambiente físiconatural. Envolve, portanto, dinâmica social e dinâmica ambiental. "Os estudos que apresentam abordagem sob a perspectiva das vulnerabilidades socioambientais contribuem para o entendimento dos problemas ambientais urbanos (...)." (Ahrens, 2003, p.75).

A vulnerabilidade devido à ocupação das chamadas APPs/ FMPs, que muitas vezes, são inundáveis, leva em conta o fator relevo e as modificações pela ocupação do solo, cujo perigo natural é reconhecido. Essa exposição faz destas áreas de reconhecida vulnerabilidade ambiental e, quando ocupadas por uma população socialmente vulnerável, é vista pelo CFB (Lei 12.651/ 2012) como passível de regulamentação ambiental, intervenção ou supressão de vegetação nativa em APP que, de acordo com o Art. $8^{\circ}$, “(...) ocorrerá nas hipóteses de utilidade pública, de interesse social ou de impacto ambiental”.

Para Zancopé (2011, p.331) “As planícies fluviais são naturalmente consideradas áreas de risco segundo diversos tipos de mapeamentos geotécnicos ou mesmo legislações específicas". São marcadas por inundações periódicas oriundas dos transbordamentos dos rios que margeiam. Sendo assim, áreas suscetíveis a inundações são áreas consideradas pela Lei 12.651/2012 como Áreas de Preservação Permanente - Faixa Marginal de curso d'água independentemente da precipitação incidente, altitude, declividade, uso da terra e tipo de solo, são áreas que se consideram de suscetibilidade (SANTOS, 2010, p.4).

Como medida de controle de inundação, Hora et al (2009, p.75) e Tominaga et al. (2009, p.160) consideram o mapeamento de áreas de risco como fundamental para o planejamento e a redução do risco de inundações ampliados com a ocupação das APPs/ FMPs. Como também são fundamentais os mapeamentos de suscetibilidades a inundações na regularização ambiental e fundiária e mapeamentos de uso da terra em APPs. 


\section{Metodologia}

\subsection{Mapeamento das APPs/ FMPs e a Análise e Caracterização do uso da terra}

Para o mapeamento foi utilizado o software ArcGis 10.3 (ESRI, 2014) e para a delimitação das APPs / FMP informações do Artigo 4ํㅜㄹ inciso I, alíneas c - d a Lei 12.651/12 (BRASIL, 2012).

Após o georreferenciamento realizado a partir de pontos demarcados em campo por GPS (Coordenada UTM) e com controle de campo, foi realizada a correção do mapa vetorial de hidrografia por fotointerpretação da segmentação do Rio Paraíba do Sul. Foi mensurada a largura das margens do rio (leito de vazante) e delimitada em três áreas estudo ao longo do rio onde as larguras das seções variam de 100 a 530 metros. As APPs / FMPs de 100 e 200 metros foram definidas a partir do leito de vazante resultando em mapeamentos de 1:10.000 na Área 1, 1:11.000 na Área 2 e 1:15.000 na Área 3 e caracterizadas a partir do Uso da terra em shappefile, disponibilizado pelo Instituto do Ambiente - INEA (INEA, 2015) e confirmação dos trabalhos de campo. Identificaram-se as classes Vegetação Arbórea, Pastagem, Pastagem em Várzea Água, Ocupação Urbana de Baixa-Média-Alta Densidade (INEA, 2015).

\subsection{Caracterização das Áreas de Inundação}

Para caracterização das Áreas de Inundação foram gerados mapas de declividade para as Áreas 1, 2 e 3 com o tratamento das imagens pelo software e a partir da hipsometria do Estado do Rio de Janeiro na escala de 1:50.000, disponibilizada pelo INEA (2015) e de imagens raster 1:40.000 (SRTM, 2015). Foram gerados três diferentes mapas com classes dos tipos de relevo classificados pela EMBRAPA (2006) na Tabela 1. Os resultados da declividade nas APPs/ FMPs das Áreas 1, 2 e 3 foram apresentados em tabelas. 
Plano: superfície de topografia horizontal, desnivelamentos pequenos, com declividades variáveis de 0 a $3 \%$.

Suave ondulado: superfície de topografia pouco movimentada, constituída por colinas, apresenta declives suaves, variando de $3 \%$ a $8 \%$.

Ondulado: superfície de topografia pouco movimentada, constituída por colinas, apresenta declives moderados, variando de $8 \%$ a $20 \%$.

Forte Ondulado: superfície de topografia movimentada, constituída por morros e raramente por colinas com declives fortes, variando de $20 \%$ a $45 \%$.

Montanhoso: superfície de topografia vigorosa, com predomínio de formas acidentadas, constituídas por morros, montanhas, maciços montanhosos e alinhamentos montanhosos com desnivelamentos grandes e declives fortes e muito fortes, variando de 45 a $75 \%$.

Escarpado: superfícies muito íngremes e escarpamentos, como frentes de cuestas, vertentes de declives muito fortes ultrapassando $75 \%$.

Tabela 1 - Tipos de Relevo segundo a EMBRAPA (2006)

Fonte: EMBRAPA (2006).

\subsection{Avaliação das possibilidades em APPs urbanas consolidadas}

Para a avaliação das possibilidades de flexibilização da delimitação das APPs consolidadas em FMPs já ocupadas ou descaracterizadas, nas três áreas de estudo utilizou-se a metodologia "Reflexos do novo Código Florestal nas Áreas de Preservação Permanente APPs - urbanas" de Azevedo et al. (2014) que trata do uso de APPs e possibilidade de flexibilização da legislação em áreas urbanas discutindo paralelamente com o que menciona o CFB, Lei 12.651/ 12 (BRASIL, 2012) e a Resolução CONAMA 369 (CONAMA, 2006), quanto a intervenção ou a supressão de vegetação nativa em APP relacionada ao Uso da terra.

Foram gerados mapas hipsométricos das Áreas 1, 2 e 3 nas escalas 1:15.000 e 1:20.000 sobrepostos em relação às FMPs de 100 metros e 200 metros e perfis transversais até a distância de 2,4 km de forma a abranger não apenas o leito de vazante e a FMP, mas também, as terras adjacentes. 


\section{Resultados e discussão}

\subsection{As APPs/ FMPs e o uso da terra a partir dos 100 e 200 metros}

Nas Figuras 6, 7 e 8 são destacadas as APPs/ FMPs de 100 metros do Rio Paraíba do Sul na Área 1 e 200 metros nas Áreas 2 e 3, utilizando como referência o leito de vazante do rio como estabelecido pelo Art.4을 Inciso I, Lei 12.651/12, aonde é evidente a ausência de cobertura vegetal e a construção de edificações na APP /FMP. Os trabalhos de campo tiveram como objetivo confirmar os usos da terra.

De acordo com a Figura 2 e a Tabela 2 que representa quantitativamente o uso da terra para a FMP de 100 metros - Área 1, em uma escala de 1:10.000, uma área de 5,57 $\mathrm{Km}^{2}$, com uso 'Ocupação Urbana de Média Densidade' e majoritariamente coberta por gramínea, o que o INEA (2015) em suas bases cartográficas classifica como 'Pastagem'. Não há cobertura vegetal é como representado. O uso 'Ocupação Urbana de Média Densidade' com 1,84 Km² e 'Pastagem' 0,89 $\mathrm{Km}^{2}$.

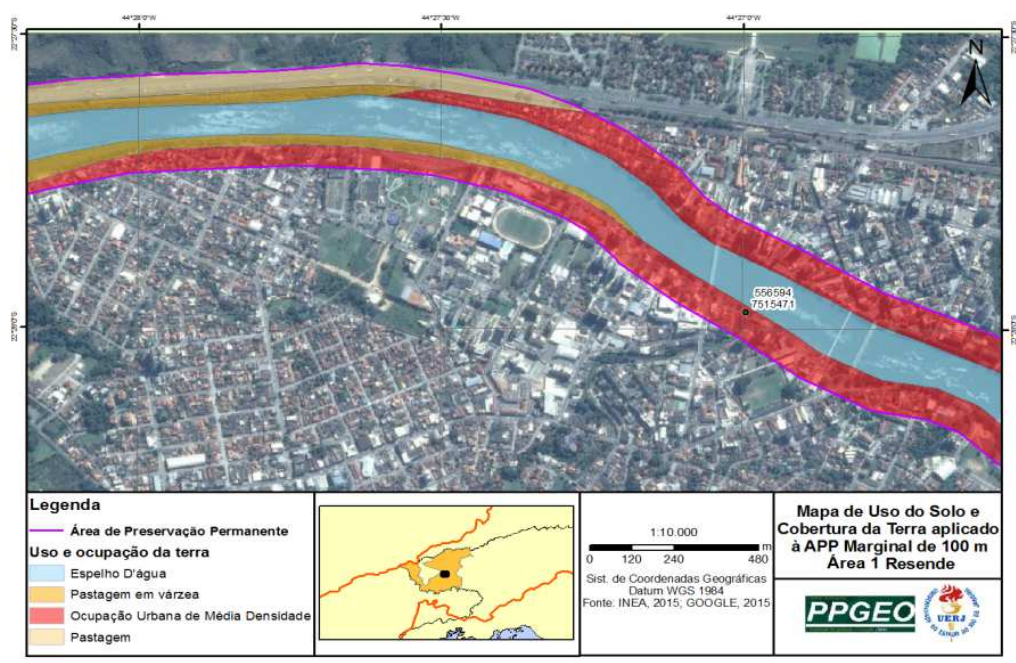

Figura 2 - Mapa de uso da terra na Área 1. Fonte: Os autores, 2016.

\begin{tabular}{ccc}
\hline Classes & Área $\left.\mathbf{( K m}^{\mathbf{2}}\right)$ & Área (\%) \\
\hline Pastagem & 0,89 & 15 \\
Água & 2,73 & 49 \\
Ocupação Urbana de Média Densidade & 1,84 & 33 \\
Pastagem em Várzea & 0,11 & 03 \\
Total & 5,57 & 100 \\
\hline
\end{tabular}

Tabela 2 - Classes de uso da terra em APP/FMP - Área 1 Fonte: Os autores, 2016. 
A Figura 3 e a Tabela 3 representa quantitativamente o uso da terra para a FMP de 200 metros em escala de 1:11.000 - Área 2. Uma área de 4,27 km², 0,91 $\mathrm{Km}^{2}$ classificado como 'Ocupação Urbana de Baixa Densidade'; 0,58 Km² 'Pastagem'; 0,05 Km² 'Vegetal Arbórea'; $2,73 \mathrm{Km}^{2}$ para 'Água'. Predomina na margem esquerda, o uso 'ocupação urbana de baixa densidade' associado a 'pastagem'e, na margem direita, predomina a 'vegetação arbórea'.

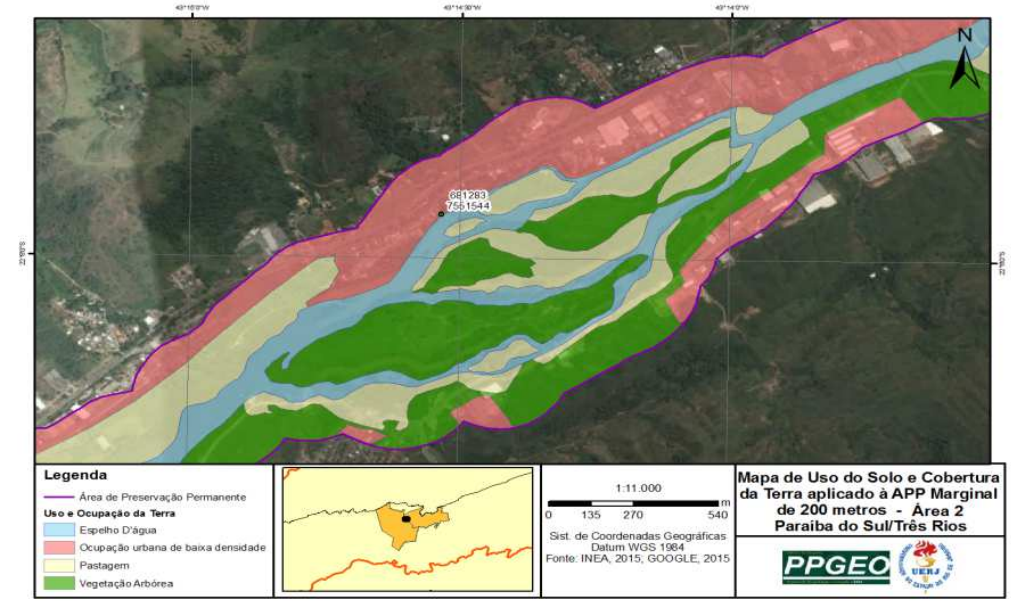

Figura 3 - Mapa de uso da terra na Área 2. Fonte: Os autores, 2016.

\begin{tabular}{ccc}
\hline Classes & Área $\left(\mathbf{K m}^{\mathbf{2}}\right)$ & Área (\%) \\
\hline Ocupação Urbana de Baixa Densidade & 0,91 & 39,77 \\
Pastagem & 0,58 & 25,08 \\
Vegetação Arbórea & 0,05 & 1,80 \\
Água & 2,73 & 33,35 \\
Total & 4,27 & 100 \\
\hline
\end{tabular}

Tabela 3 - Classes de uso da terra em APP/FMP - Área 2 Fonte: Os autores, 2016.

Na Figura 4 é representada a faixa que corresponde APP/ FMP de 200 metros na escala de 1:15.000 - Área 3 e a Tabela 4 representa quantitativamente o uso da terra para a FMP. No total de 3,01 $\mathrm{Km}^{2}$ predominam a 'Ocupação Urbana de Alta Densidade" e 'Pastagem', os $1,51 \mathrm{Km}^{2}$ são classificados como 'Ocupação Urbana de Alta Densidade', 0,33 Km² são utilizados para 'Pastagem', 0,07 Km² de 'Área Úmida' e 1,10 Km² 'Água'. 


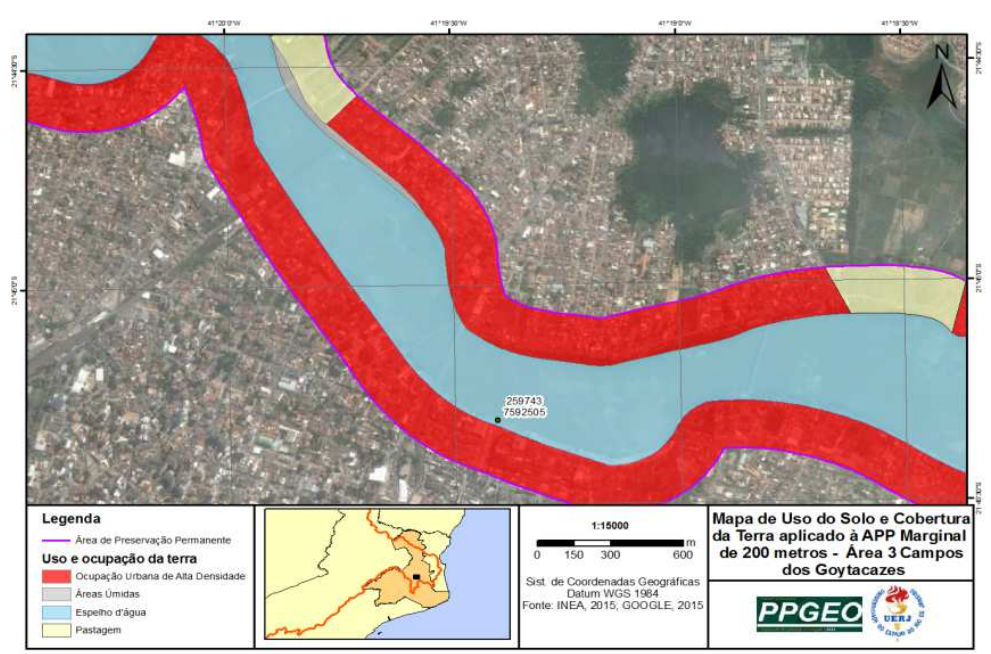

Figura 4 - Mapa de uso da terra em APP/ FMP de 200 metros do Rio Paraíba do Sul na Área 3 Fonte: Os autores, 2016.

\begin{tabular}{ccc}
\hline Classes & Área $\left(\mathbf{K m}^{\mathbf{2}}\right)$ & Área $\mathbf{( \% )}$ \\
\hline Ocupação Urbana de Alta Densidade & 1,51 & 50,4 \\
Área Úmida & 0,07 & 2,2 \\
Água & 1,10 & 36,5 \\
Pastagem & 0,33 & 10,9 \\
Total & 3,01 & 100 \\
\hline
\end{tabular}

Tabela 4 - Classes de uso da terra em APP/FMP - Área 3 Fonte: Os autores, 2016.

\subsection{As Áreas de Inundação nas três Áreas estudadas}

São caracterizadas pela ocupação dos espaços susceptíveis, como o leito maior e leito maior excepcional do Rio Paraíba do Sul. As pesquisas de campo realizadas evidenciam a recorrência de enchentes e inundações em ambas as áreas.

Na APP/ FMP de 100 metros do Rio Paraíba do Sul na da Área 1, apresentada pela Figura 5, o relevo é 'Plano' possui uma classe do relevo com declividade de 0 a $3 \%$. 


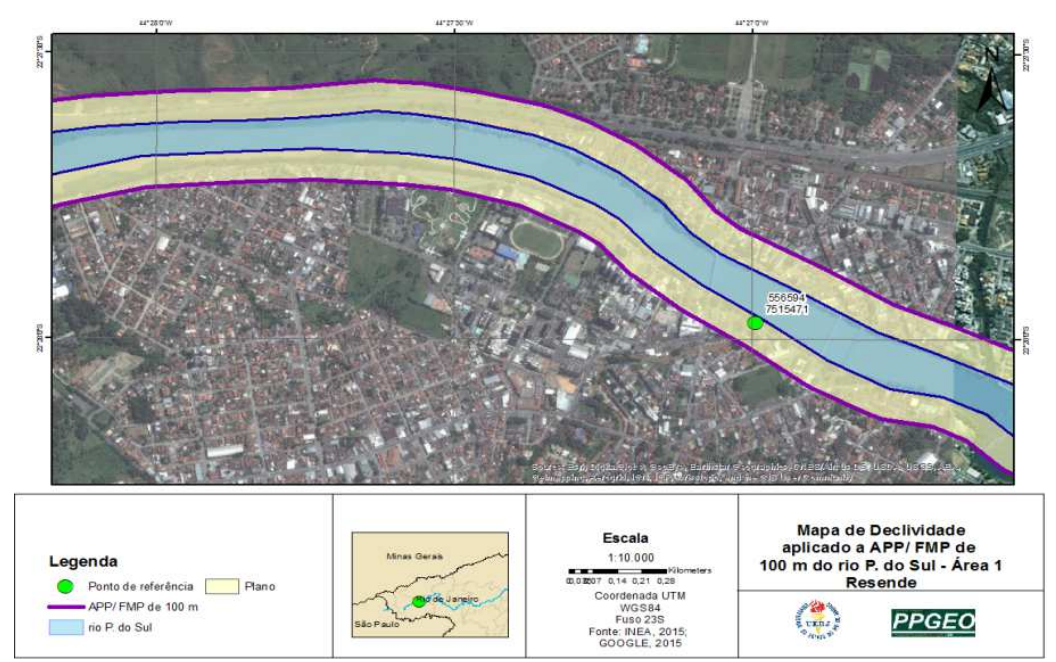

Figura 5 - Declividade aplicada a APP/ FMP do Rio P. do Sul na Área 1. Fonte: Os autores, 2016.

\begin{tabular}{ccc}
\hline Classes & Área $\left(\mathbf{K m}^{\mathbf{2}}\right)$ & Área (\%) \\
\hline Plano & 5,57 & 100 \\
Total & 5,57 & 100 \\
\hline
\end{tabular}

Tabela 5 - Classes do Relevo em APP/ FMP do Rio Paraíba do Sul na Área 1 Fonte: Os autores, 2016.

Na Figura 6 apresenta-se o Mapa de Declividade APP/ FMP de 200 metros do Rio Paraíba do Sul na Área 2, com as classes de declive 'Plano', 'Suave Ondulado', 'Ondulado', 'Forte Ondulado', 'Montanhoso 'e 'Escarpado'. A Tabela 6, os 2,30 $\mathrm{Km}^{2}$ possuem classes do relevo com uma variação da declividade de 0 a $>75 \%$. A classe 'Plano' com 1,55 Km², 'Suave Ondulado' 0,34 $\mathrm{Km}^{2}$, ‘Ondulado' 0,23 km², ‘Forte Ondulado' 0,15 Km², 'Montanhoso' 0,01 $\mathrm{Km}^{2}$ e 'Escarpado' 0,0002 $\mathrm{Km}^{2}$.

Demonstra-se o declive plano e suavemente ondulado próximo ao leito maior e de vazante do Rio Paraíba do Sul e a tendência ao aumento da declividade a medida que se afasta do leito de vazante e a diminuição, a medida que se aproxima. Favorece o uso 'Ocupação Urbana de Baixa Densidade' e uma maior concentração demográfica quanto mais próxima ao Leito de Vazante e a margem esquerda e, também, onde há maior suscetibilidade a inundações. 


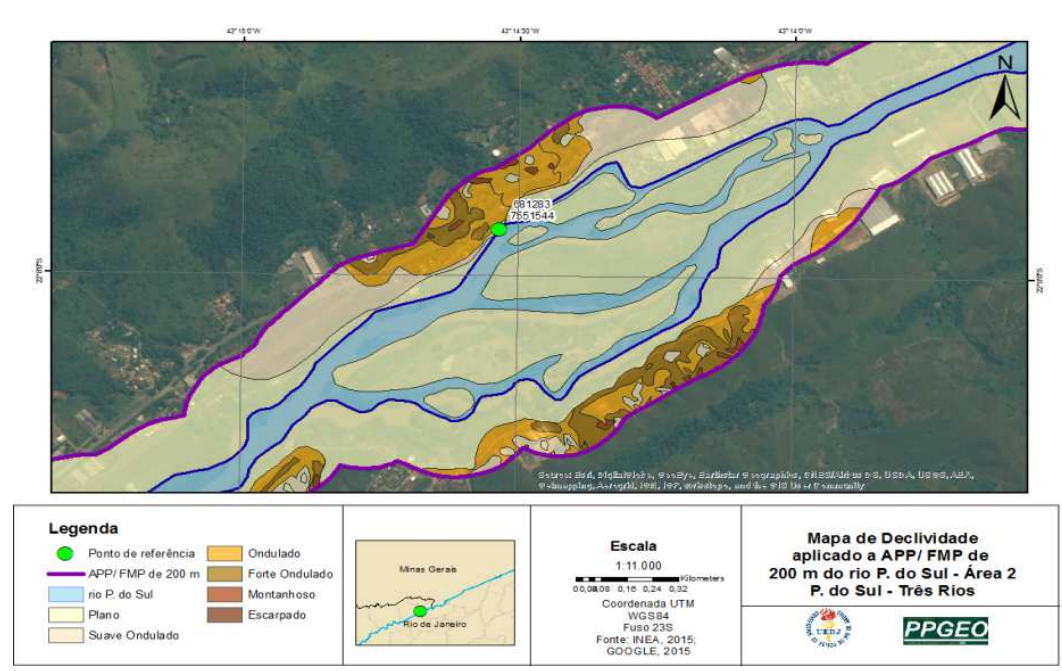

Figura 6 - Declividade aplicada à APP/ FMP do Rio P.do Sul na Área 2. Fonte: Os autores, 2016.

\begin{tabular}{ccc}
\hline Classes & Área $\left.\mathbf{( K m}^{\mathbf{2}}\right)$ & Área (\%) \\
\hline Plano & 1,55 & 67,61 \\
Suave Ondulado & 0,34 & 14,76 \\
Ondulado & 0,23 & 10,1 \\
Forte Ondulado & 0,15 & 6,73 \\
Montanhoso & 0,01 & 0,77 \\
Escarpado & 0,0002 & 0,01 \\
Total & 2,30 & 100 \\
\hline
\end{tabular}

Tabela 6 - Classes do Relevo em APP/ FMP do Rio P. do Sul na Área 2 Fonte: Os autores, 2016.

Na APP/ FMP de 200 metros do Rio Paraíba do Sul na Área 3 apresentada pela Figura 7 na escala de 1:15.000, a classe do relevo é 'Plano' nos 3,01 km². Há presença de uma planície de inundação fluvial extensa conhecida como baixada campista, facilita e condiciona a ocupação na faixa que compreende tanto os 200 metros como toda a extensão da Área 3 (Figura 7). Os dados são melhores ilustrados pela Tabela 6. 


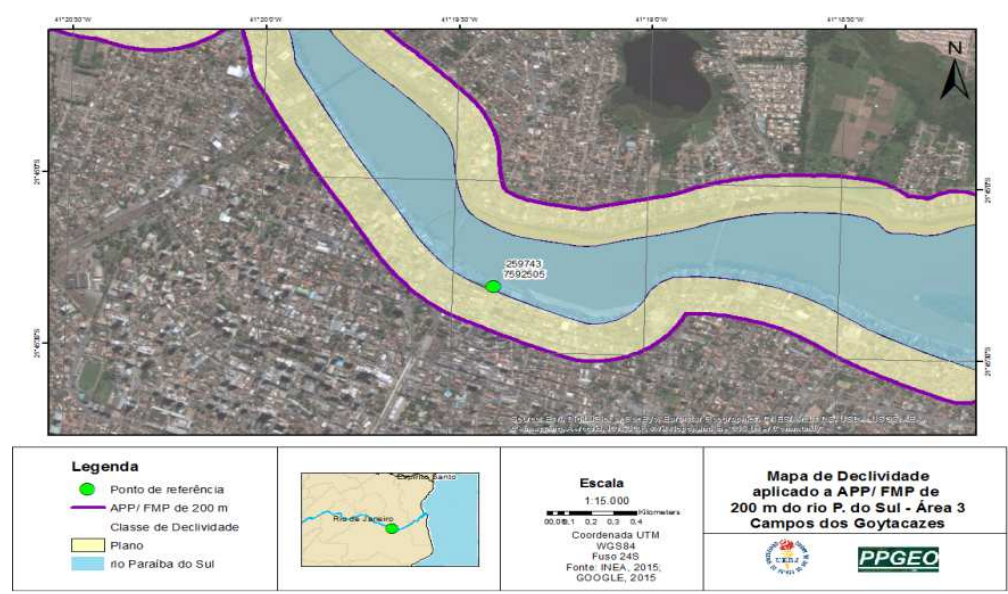

Figura 7 - Declividade da APP/ FMP do Rio P. do Sul na Área 3 Fonte: Os autores, 2016.

\begin{tabular}{ccc}
\hline Classes & Área $\left(\mathrm{Km}^{\mathbf{2}}\right)$ & Área (\%) \\
\hline Plano & 3,01 & 100 \\
Total & 3,01 & 100 \\
\hline
\end{tabular}

Tabela 7 - Classes do Relevo em APP/ FMP do Rio P. do Sul na Área 3 Fonte: Os autores, 2016.

Os levantamentos de campo realizados nas Áreas 1, 2 e 3 e o material cartográfico gerado por SIG indicam áreas com baixas declividades suscetíveis a inundações. E na proximidade com o leito de vazante do Paraíba do Sul, é possível observar que as declividades são baixíssimas, sobretudo nas Áreas 1 e 3, com o relevo 100\% plano. Na Área 2, o aparecimento de várias classes de declive nesta faixa denunciam a ocorrência de outras categorias de APP além da FMP.

\subsection{Vulnerabilidade à Ocupação da APP/ FMP nas três Áreas estudadas}

As três áreas de estudo encontram-se em uma região urbanizada, onde os processos físicos do meio e dos usos da terra (urbano impermeabilizado), acarreta em inundações e enchentes, devido a ocupação do leito maior e da área legalmente protegida, a APP/ FMP de até 100 metros na Área 1, 200 metros na Área 2 e na Área 3. A área compreendida caracteriza o expressivo uso 'urbano' ou 'ocupação de baixas, médias e altas densidades' (INEA, 2015) anteriormente demostradas pelos Mapas de uso da terra para as FMPs das Áreas 1, 2 e 3 pelas Figuras 2, 2 e 4. 
Os trabalhos de campo evidenciaram a vulnerabilidade da ocupação das margens do Rio Paraíba do Sul com as inundações deste rio nos municípios de Resende, Paraíba do Sul-Três Rios e em Campos dos Goytacazes. E diversas ocorrências são registradas pelas notícias dos jornais das Áreas 1, 2 e 3, como mapeamentos que demonstram as classes de uso da terra nas APPs/ FMPs, havendo, portanto, uma confirmação da vulnerabilidade à Ocupação da APP/ FMP nas três áreas. As inundações e os danos causados são históricos, datam de 1943, 1966 e 2007 quando o nível da água atingiu o maior nível já registrado 11,64 metros em Campos dos Goytacazes (URURAU, 2012).

\subsection{Possibilidades de ocupação de APPs de FMP nas três Áreas urbanas consolidadas}

O CFB, Lei 12.651/ 12 (BRASIL, 2012), determina que a intervenção ou a supressão de vegetação nativa em APP poderá ser autorizada nas hipóteses de utilidade pública, de interesse social ou de baixo impacto ambiental. Contudo, a norma alterou alguns aspectos do regime de proteção das APPs de utilidade pública e de interesse social.

Demonstrou-se que a Lei 12.651/2012, em comparação com antigo CFB e a Resolução CONAMA 369 (CONAMA, 2006), aumentou as hipóteses de casos excepcionais de utilidade pública e de interesse social. Além disso, para intervenções em APPs nos casos de utilidade pública e de interesse social "não mais se exige a comprovação de inexistência de alternativas" (AZEVEDO et al., 2014, p.15).

Nas Áreas 1, 2 e 3 há utilização de APPs/ FMPs para atendimento a critérios econômicos, como por exemplo, uso urbano e especulação imobiliária, em detrimento do controle ambiental ou do bem estar da população. A FMP em ambas as áreas de estudo possui um uso de 'Ocupação Urbana', de Alta densidade na Área 3 e Média densidade nas Áreas 1 e 2, o que se sobrepõe ao que se denomina exceção de utilidade pública, de interesse social ou de baixo impacto ambiental.

Verificou-se que, as três Áreas estudadas (1, 2 e 3), são Áreas Urbanas já consolidadas no Estado do Rio de Janeiro e são APPs urbanas. Na Área 3 predomina o Uso Urbano de 'Ocupação de Alta Densidade' e uma população com atividades e serviços ditos urbanos e construções de alto padrão comercial nas Áreas 1 e 3. E na Área 2 há a regularização 
fundiária de assentamentos humanos ocupados predominantemente por população de baixa renda em área urbana consolidada na margem esquerda do Rio Paraíba do Sul.

Há aumentos significativos do adensamento urbano o que possibilita uma utilização de APPs nos casos de utilidade pública e de interesse social. Estas três áreas tiveram abrandamento da preservação ambiental de forma a atender interesses econômicos e sociais. Consequentemente, essas alterações vulneram, de modo significativo, a proteção das APPs/ FMPs e, especificamente, nas Áreas 1, 2 e 3 situadas em áreas urbanas já consolidadas.

De acordo com as Figuras 8, 9 e 10 como também nos Perfis Transversais demonstrados (Gráficos 1, 2 e 3) estas três áreas são áreas de inundação do Paraíba do Sul, ou seja, são os leitos do rio. E as FMPs recomendadas pelo CFB são de baixas altimetrias e possibilitam a ocupação urbana.

De acordo com a Figura 8, na Área 1, o Rio Paraíba do Sul atravessa o relevo encaixado e a planície do rio é vista pelo Gráfico 1, um Perfil Transversal que demonstra que os 100 metros de faixa marginal são de fato importantes para a função de APP/ FMP. Não havendo a necessidade de expandi-las, pois sobrepõe a outras categorias de Área de Preservação Permanente. Já na Área 3, as FMPs são as únicas categorias de APPs existentes.

As FMPs de 100 e 200 metros mencionadas no CFB, consideradas como padrões para largura mínima do rio desde a borda regular ou leito de vazante, são calculadas com referência numérica a larguras mínimas. Portanto, há necessidade e/ou possibilidade de ampliá-las e discuti-las nas Áreas 1, 2 e 3. Neste caso o padrão de drenagem fluvial e as características geomorfológicas têm de serem avaliadas em ambas as Áreas.

As Áreas 1, 2 e 3 referem-se justamente a três diferentes cenários e recortes geomorfológicos do Rio Paraíba do Sul em seu alto, médio e baixo curso no Estado fluminense. O controle geológico do seu leito na Área 2 faz que o rio ocupe todo o leito de vazante, o leito maior e o leito maior esporádico. E, portanto, a APP/ FMP, que também ocorre nas Áreas 1 e 3.

De acordo com a Figura 9, que demonstra o Perfil Transversal (Gráfico2) da Área 2, toda a FMP de 200 metros do Paraíba do Sul é considerada leito do rio. Nesta seção, curso médio, 
o rio ocupa a planície inundável/ leito maior esporádico. Os 200 metros entram em confronto com outras categorias de APP. As APPs de encosta e APPs de topo de morro.

A Figura 10 e Gráfico 3 demonstram o Perfil Transversal da Área 3, em uma área de declive totalmente Plano, os 200 metros recomendados são insuficientes pelas características geomorfológicas deste recorte espacial. A FMP, os leitos do Paraíba do Sul e inclusive o leito maior esporádico, possuem uma altíssima suscetibilidade a inundação. As FMPs são, portanto, ocupadas pelas águas que se espraiam e a ausência de controle geológicogeomorfológico, as baixas cotas altimétricas no baixo curso do rio são os condicionantes.

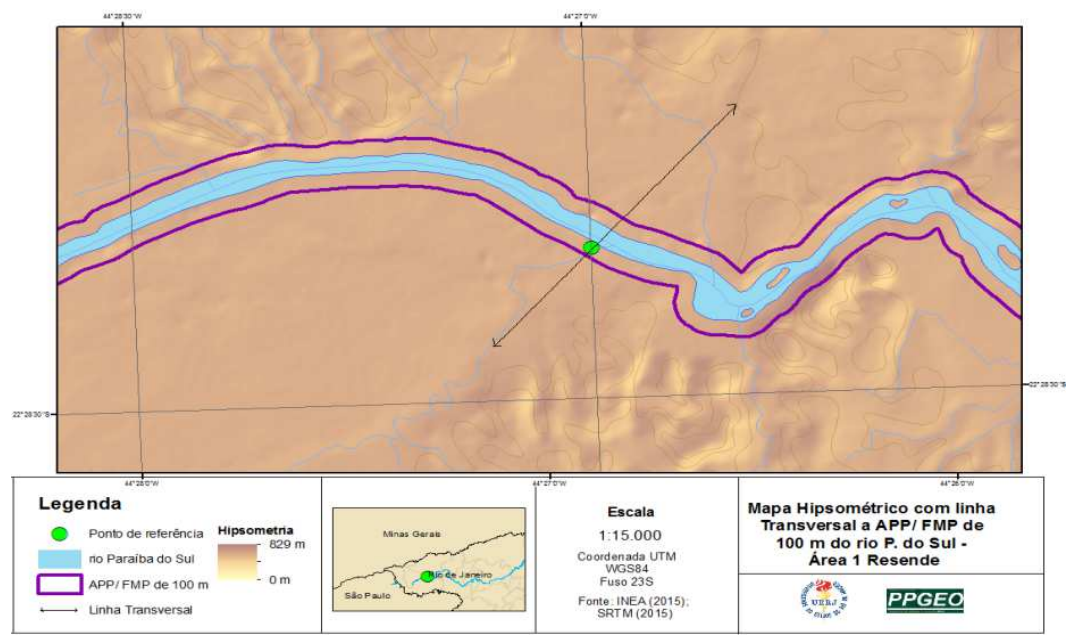

Figura 8 - Hipsometria da Área 1 com a linha Transversal. Fonte: Os autores, 2015.

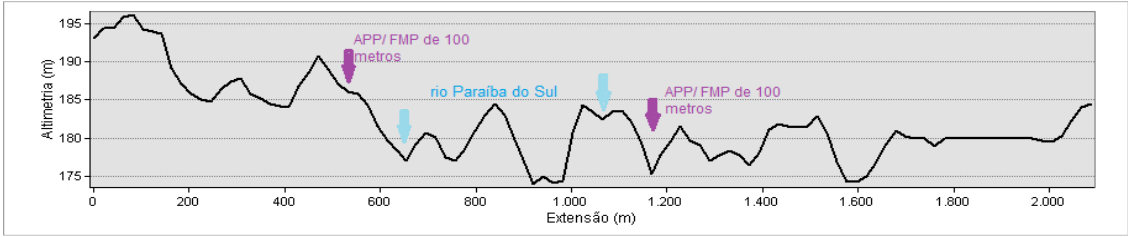

Gráfico 1 - Perfil Transversal da Área 1 com a indicação da APP/ FMP de 100 metros e do Rio Paraíba do Sul.

Fonte: Os autores, 2015. 


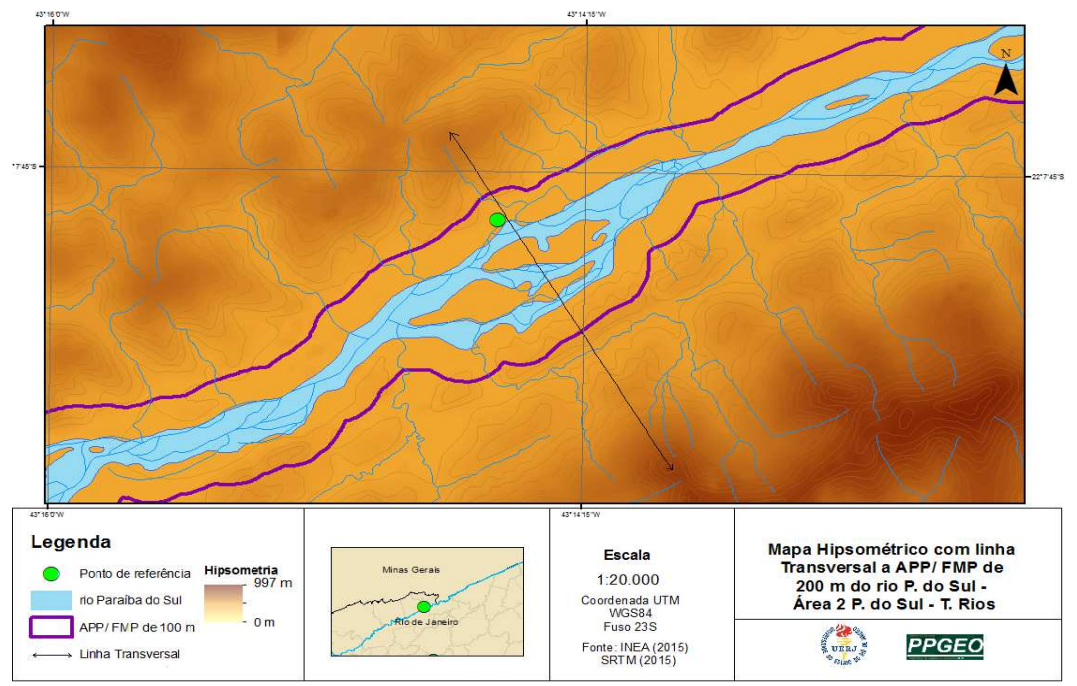

Figura 9 - Hipsometria da Área 2 e a linha Transversal. Fonte: Os autores, 2016.

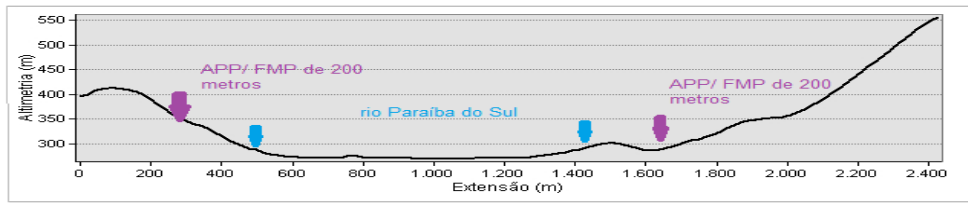

Gráfico 2 - Perfil Transversal da Área 2 com a indicação da APP/ FMP de 200 metros e do Rio Paraíba do Sul.

Fonte: Os autores, 2016.

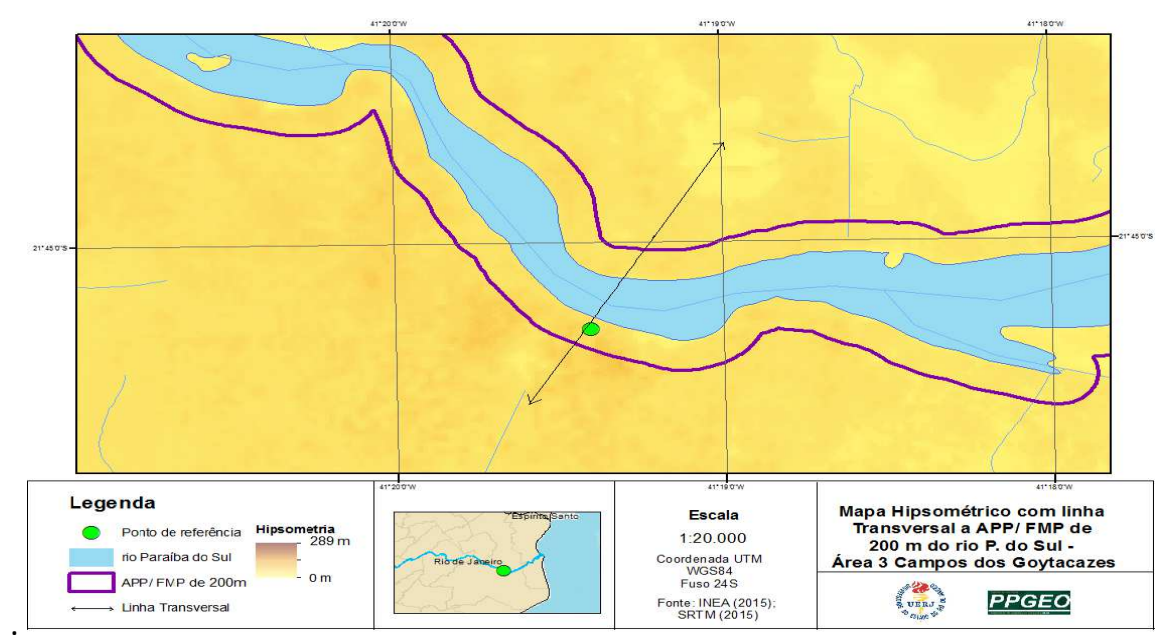

Figura 10 - Hipsometria da Área 3 e a linha Transversal Fonte: Os autores, 2016.

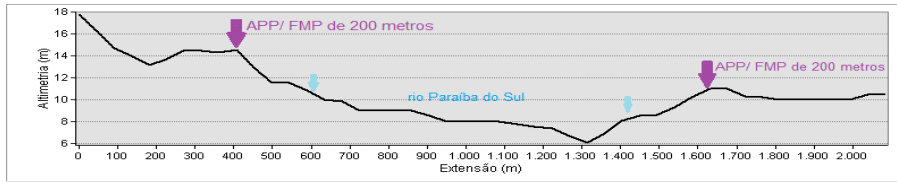

Gráfico 3 - Perfil Transversal da Área 3 com a indicação da APP/ FMP de 200 metros e do Rio Paraíba do Sul. Fonte: Os autores, 2016. 


\section{Conclusão}

As Áreas 1, 2 e 3 apresentam ocupação urbana de alta (Área 3) e média densidade (Área 1 e 2) com graus de impermeabilização do solo e ausência de cobertura da terra. Há grandes dificuldades na interpretação das normas que regulam as APP nestas áreas urbanas, especialmente, nestas FMPs no que se refere aos limites mínimos. Nas três áreas estudadas, as FMPs de limites mínimos de 100 e 200 metros fixados não são facilmente aplicadas frente à realidade urbana.

As FMPs estabelecidas pelo Art. 4 do CFB são mínimas e aplicam-se integralmente nestas áreas urbanas como também em áreas rurais. Uma vez que, a APP é uma área protegida, coberta ou não por vegetação nativa, tem a função ambiental de preservação. Desta maneira, o que se observa é que, mais importante que ajustar os limites mínimos para estas FMPs, é solucionar as imprecisões relacionadas à autorização à supressão de vegetação e a ocupação destas áreas de risco, suscetíveis a inundações. Como também, ajustar a infraestrutura e atividades para a preservação e manutenção da cobertura vegetal e das FMPs, realizando um ordenamento territorial que se refere ao uso da terra ao longo das FMPs do Rio Paraíba do Sul, áreas que já são ocupadas, analisando o regime hídrico, a geologia, o uso da terra e a cobertura da terra.

Com isso, devem ser observados os casos de utilidade pública ou interesse social bem como os limites fixados para as FMPs nos aglomerados subnormais ${ }^{1}$ vulneráveis na Área 2 e nos grandes empreendimentos imobiliários nas Áreas 1 e 3, que impõe uma regularização urbana de interesse social e de utilidade pública à supressão da vegetação e a autorização para ocupação destas áreas suscetíveis a inundação e com classe do relevo plano e suave ondulado no Estado do Rio de Janeiro.

A partir dos dados levantados e das observações de campo, na Área 1, os 100 metros de largura mínima estabelecidos pela legislação são suficientes dada as dimensões do Rio Paraíba do Sul, no entanto, a ocupação urbana não respeita este limite, existindo, em alguns trechos, apenas uma rua entre as edificações e o leito do rio. Na Área 2, os 200 metros estabelecidos para a APP excedem o que se considera como largura mínima, pois o rio mais

\footnotetext{
${ }^{1}$ Áreas conhecidas no Brasil por diversos nomes, como favela, comunidade, grotão, vila, mocambo, entre outros (IBGE, 2010).
} 
encaixado cria condições para a APP/ FMP se sobreponha a outras categorias de APP, tais como, APP topos de morros e APP de encosta. E na Área 3, por ser uma planície flúviomarinha, os 200 metros mínimos considerados pela legislação não são suficientes. A extensa planície do Rio Paraíba do Sul cria condições para que uma grande área seja inundada, caso o rio saia do seu leito.

Diante dos dados apresentados pode-se apresentar uma conclusão final de que é possível alterar a dimensão das APPs/ FMPs. Nas três áreas apresentadas veem-se exemplos de que nas seções onde a drenagem está mais encaixada, seria possível reduzir a dimensão da FMP. Por outro lado, nas áreas de planícies fluviais mais extensas, deveria ser ampliada.

Finalmente, recomenda-se que sejam elaborados estudos detalhados quando for feita a solicitação de intervenção nas APPs/ FMPs.

\section{Referências bibliográficas}

AHRENS, S. O "Novo" Código Florestal Brasileiro: conceitos jurídicos fundamentais. In: CONGRESSO FLORESTAL BRASILEIRO, 8, 2003. Anais... São Paulo: SBS; Brasília: SBEF, 2003.

ARAÚJO, S.M.V.G. As áreas de preservação permanente e a questão urbana. Estudo. Brasília, Câmara dos Deputados/ Consultoria Legislativa, 2002.

AZEVEDO, R. E. S. de; OLIVEIRA, V. P. V. de. Reflexos do novo Código Florestal nas Áreas de Preservação Permanente - APPs - urbanas. Revista Desenvolvimento e Ambiente, Curitiba, v. 29, p. 71-91, abril 2014.

BORGES, L. A. C. Aspectos técnicos e legais que fundamentam o estabelecimento das áreas de preservação permanente (APP). 2008. Tese (Doutorado em Engenharia Florestal)-Universidade Federal de Lavras- UFLA, Lavras: 2011.

BRAGA, T.M.; OLIVEIRA, E.L. de; GIVISIEZ, G. H. N. Avaliação de metodologias de mensuração de risco e vulnerabilidade social a desastres naturais associados à mudança climática. In: XV Encontro Nacional de Estudos Populacionais, 2006, Caxambu, ABEP. Anais..., Caxambu, 2006. Disponível em < www.abep.nepo.unicamp.br/encontro2006/docspdf/ABEP2006.pdf>

BRASIL. Lei no 12.651, de 25 de maio de 2012. Institui o Novo Código Florestal. Diário Oficial da União, Brasília, DF, 28 maio 2012.

BRASIL. Lei no 4.771, 15 de setembro de 1965. Institui o novo Código Florestal. Diário da República Federativa do Brasil, Brasília, DF, 16 set. 1965.

BRASIL. Ministério das Cidades. Instituto de Pesquisas Tecnológicas. Mapeamento de riscos em encostas e margens de rios. Brasília: Ministério das Cidades; Instituto de Pesquisas Tecnológicas, 2007.

BRASIL. Ministério do Meio Ambiente. Relatório de inspeção: área atingida pela tragédia das chuvas na Região Serrana do Rio de Janeiro: áreas de preservação permanente e unidades de conservação $x$ áreas de risco: 0 que uma coisa tem a ver com outra? Brasília: MMA, 2011. 
CONAMA. Resolução CONAMA no 369, de 28 de março de 2006. Dispõe sobre os casos excepcionais, de utilidade pública, interesse social ou baixo impacto ambiental, que possibilitam a intervenção ou supressão de vegetação em Área de Preservação Permanente. Diário Oficial da União, n. 61, Seção 1, p. 150-151, 29 mar. 2006.

COSTA, J. M. L. M. Estudo teórico sobre a determinação de Áreas de Preservação Permanente (APPs) marginais ao curso d'água através da análise de fatores ambientais no âmbito da bacia hidrográfica: enfoque geomorfológico. 2010. Dissertação (Mestrado)-Universidade do Estado do Rio de Janeiro, 2010a.

COSTA, L.M. S. A.; VESCINA, L.; MACHADO, D. B. P. M. Environmental restoration of urban rivers in the metropolitan region of Rio de Janeiro, Brazil. Urban Environment. Montreal (Quebec) Canadá. v. 4, n.1, p. 1326. 2010b.

EMBRAPA. Centro Nacional de Pesquisa de Solos. Sistema brasileiro de classificação de solos - Rio de Janeiro, Escala 1:80.000. Rio de Janeiro: EMBRAPA-SPI, 2006.

ESRI. Environmental Systems Research Institute, Inc. ArcGIS. Professional GIS for the desktop, versão 10.3 CA. ArcGis. 2014.

HORA, S.; GOMES, R. L. Mapeamento e avaliação do risco a inundação do Rio Cachoeira em trecho da área urbana do Município de Itabuna/BA. Sociedade \& Natureza, Uberlândia, v. 21, n. 2, p. 57-75, 2009.

IBGE. Instituto Brasileiro de Geografia e Estatística. Censo 2010: Aglomerados Subnormais - Informações Territoriais. Rio de Janeiro: IBGE, 2010.

INEA. Instituto Estadual do Ambiente. Base de Dados uso do solo e cobertura da Terra. 1:50.000. Rio de Janeiro: INEA, 2015.

MACHADO, P. J. de O. Diagnóstico ambiental e ordenamento territorial: instrumentos para a gestão da Bacia de Contribuição da Represa de Chapéu D’Uvas/MG. 2012. Tese (Doutorado em Geografia)-Universidade Federal Fluminense, Niterói, 2012.

RESENDE, K. M. Legislação Florestal Brasileira: uma reconstituição histórica. 2006. 150f, il. Dissertação (Mestrado)-Universidade Federal de Lavras, Lavras, 2006.

SANTOS, A. R. dos; LOUZADA, F. L. R de O.; EUGENIO, F. C. ArcGIS 10.3 Total: aplicações para dados especiais. Alegre, ES: Ciências Agrárias Universidade Federal do Espírito Santo/CAUFES, 180 p., 2010.

SILVA, A. S. da. Mineração e áreas de preservação permanentes (APPs) em Santo Antônio De Pádua - RJ. Revista Sociedade \& Natureza, Uberlândia, ano 23 n. 2, 173-185, maio/ago. 2011.

SRTM. Shuttle Radar Topography Mission. Monitoramento por Satélite. Imagens de 1:80.000. Disponível em <embrapa.gov.br>.

TOMINAGA, L. K.; SANTORO, J.; AMARAL, R. (Org.). Escorregamentos e Inundações e Enchentes. In: SÃO PAULO. Secretaria de Meio Ambiente. Instituto Geológico. Desastres Naturais: conhecer para prevenir. São Paulo: Instituto Geológico, p. 25-52. 2009.

URURAU. Inundação em Campos, 12 de janeiro de 2012. Disponível em <www.ururau.com.br/cidades10496> Acesso em out.2015.

ZANCOPÉ, M.H.C. Riscos e danos ambientais no contexto da geomorfologia fluvial. Gestão de Áreas de Riscos e Desastres Ambientais. 1.ed. Rio Claro: IGCE/UNESP/RIO CLARO, 2012. p. 328. 